\title{
La música de sanación en comunidades asháninkas de la cuenca del río Tambo
}

\author{
Healing music in the Asháninka communities of the Tambo river basin
}

\author{
Beatriz Anastacia Fabián Arias 1,a \\ https://orcid.org/0000-0002-4978-0808
}

Recibido: 18-11-2020

Aceptado: 01-01-2021

\section{Citar como}

Fabián, B. A. (2021). La música de sanación en comunidades asháninkas de la cuenca del río Tambo. Desafíos, 12(1); 58-66. https://doi. org/10.37711/desafios.2021.12.1.272

\section{RESUMEN}

La investigación planteó como objetivo determinar las principales características de la música de sanación en comunidades asháninkas de la cuenca del río Tambo, distrito de Río Tambo, provincia de Satipo, en la selva central de Junín. La investigación es cualitativa, tipo aplicada, nivel exploratorio, método etnográfico, diseño no experimental. Los instrumentos utilizados fueron la guía de entrevista y la guía de observación; la epistemología que sustenta la investigación es la teoría histórico-cultural de Lev Semionovich Vigotsky. La muestra representativa fueron 30 participantes. Las principales características halladas fueron la ritual, medicinal, estética, interpretado con instrumentos musicales tradicionales y comunitaria. Se concluye que la música es ritual ya que es religiosa y el bosque un templo de espíritus. Es medicinal, porque sanas enfermedades psicosomáticas. Es estética porque el sheripiari es compositor y guía espiritual. Es interpretado con instrumentos musicales tradicionales mediante códigos propios. Es comunitaria, porque es festiva en la comunidad.

Palabras clave: territorio; sheripiari; música; ícaros.

\footnotetext{
ABSTRACT

The objective of the research was to determine the main characteristics of healing music in the Ashaninka communities of the Tambo river basin, district of Río Tambo, province of Satipo, in the central jungle of Junín. The research is qualitative, applied type, exploratory level, ethnographic method, non-experimental design. The instruments used were the interview guide and the observation guide; the epistemology that supports the research is the cultural-historical theory of Lev Semionovich Vigotsky. The representative sample consisted of 30 participants. The main characteristics found were ritual, medicinal, aesthetic, performed with traditional musical instruments and communitarian. It is concluded that the music is ritual because it is religious and the forest is a temple of spirits. It is medicinal, because it heals psychosomatic illnesses. It is aesthetic because the sheripiari is a composer and spiritual guide. It is interpreted with traditional musical instruments using their own codes. It is communitarian, because it is festive in the community.

Keywords: territory; sheripiari; music; icarus.
} 


\section{INTRODUCCIÓN}

El chamanismo está extendido en toda la cuenca amazónica de América Latina y es un avance el reconocimiento al territorio de los chamanes jaguares del río Pirá-Paraná (Colombia) por la Organización de las Naciones Unidas para la Educación, la Ciencia y la Cultura (UNESCO, 2011).

La práctica curativa de los chamanes o sheripiaris del pueblo asháninka consiste en formar a los niños aspirantes hasta obtener el nivel intelectual más alto, orientado a interactuar como intermediario entre el ser humano y los espíritus de la naturaleza y desenvolverse con éxito en el bosque tropical. La investigación deslinda con la visión colonial de la cultura occidental que presenta a los pueblos indígenas u originarios como gente salvaje, ociosa, sin conocimientos; cuando estos pueblos tienen una racionalidad distinta a la cultura occidental (Fabián, 2016). Por ello, es importante la incorporación del enfoque intercultural en el Ministerio de Salud.

Asimismo, se evidenció la ausencia de investigaciones sobre el tema y se trabajó con fuentes bibliográficas de algunas universidades de América Latina y España. El problema de la investigación por consiguiente fue ċuáles son las principales características de la música de sanación en comunidades asháninkas de la cuenca del río Tambo? Resaltamos que la música de sanación del pueblo Asháninka tiene una visión holística desde el contexto histórico y cultural, asociada al uso racional de los recursos del bosque y quienes rompen las reglas sufren enfermedades psicosomáticas, cuya práctica fue desarrollada durante el Tawantinsuyo. El objetivo planteado en la investigación fue determinar las principales características de la música de sanación en comunidades Asháninka de la cuenca del río Tambo, distrito de Río Tambo, provincia de Satipo, en la selva central de Junín.

\section{MÉTODOS}

Se utilizó el método etnográfico para comprender los patrones culturales del pueblo asháninka de la cuenca del río Tambo; ejemplo: ¿cómo desarrolla la purificación del cuerpo antes de ingresar a los lugares sagrados? Murillo y Martinez (2010) señalan que la investigación etnográfica se realiza con miras a comprender una realidad, analizar e interpretar lo que hacen, dicen y piensan los actores, y cómo estos interpretan la realidad desde el medio en el que viven. Por razones laborales viví en las comunidades asháninka de la cuenca del río Tambo y los pobladores me brindaron sus testimonios de buena voluntad, como señala Hammersley y Atkinson (1995), el etnógrafo busca integrarse lo máximo posible en el grupo para realizar la investigación y vivir en dos mundos simultáneamente; como participante y como investigadora y después de realizar la entrevista en profundidad con los pobladores, tomé apuntes en una libreta de campo que, más tarde, fue procesada en el gabinete.

\section{Antecedentes}

Domico-Murillo (2019) señala que el pueblo embera de Chigorodó (Colombia) estos tienen cinco tipos de cantos ancestrales, como cantos de animales, cantos de sanación, cantos de duelos, cantos de arrullos y cantos de parejas. La enseñanza y la práctica de estos conocimientos lo realizan las mujeres embera, que son las guardianas y pedagogas de la sabiduría ancestral.

Alegría (2018) explica la importancia de la música chamánica y los cantos o "ícaros" para la sanación en rituales del yagé (ayahuasca) en el contexto cultural de las comunidades del Putumayo y Caquetá (Colombia). Los chamanes son llamados magos, sacerdotes, curanderos, místicos y terapeutas que realizan danzas ceremoniales con instrumentos membranófonos para ingresar a un estado modificado de la conciencia y conectarse con mundos invisibles y traer desde esos espacios una información valiosa para la sanación de su pueblo.

López (2016) señala que la ceremonia empieza después de que los participantes bebieron la ayahuasca y tras un ícaro se genera el silencio y oscuridad. El chamán canta el ícaro Ayahuasca mariri', para invocar la 'fuerza' de la planta. La música es un pretexto para ingresar al estado de trance y la mayoría de chamanes cantan con regularidad en toda la ceremonia, mientras otros cantan sólo algunos ícaros, para no interrumpir el ritmo de los pacientes.

Sánchez (2011) explica que el chamán, en un estado de alteración de la conciencia (EAC), canta los ícaros cuya letra evoca e invoca a los espíritus y toca la música del tambor y cascabeles para acceder al mundo celeste o al submundo para contactar con los espíritus y recabar la información que requiere para curar, para equilibrar su energía física y espiritual, porque la totalidad del cuerpo está interconectado.

Lagunas (2011) explica que los chamanes indígenas y mestizos de Loreto y Ucayali curan principalmente con ayahuasca, tabaco y otras plantas psicotrópicas. Los aspirantes aprenden los poderes de los ícaros, cada uno son transmitidos por los espíritus de las plantas y cada planta enseña 
al chamán una canción de poder y sanación. También es transmitido por los espíritus de los animales, piedras, lagos o espíritus de los chamanes y vegetalistas fallecidos. Resalta la jerarquía de ícaros, cada chamán tiene un ícaro principal y los ícaros cantados en kichua, kokama u omagua tienen poder.

Quirce (2010) señala que el chamanismo tiene el contacto con el mundo de los dioses a través de una herbología enteogénica, danzas y música ritualística. El chamanismo utiliza las plantas enteogénicas para entrar en el mundo de los dioses y ancestros. El tabaco es utilizado para transportar al paciente a un estado de felicidad enteogénica por muchas horas, la enfermedad es derrotada por ese estado diferenciado de conciencia, ahuyentado a los espíritus de la enfermedad e invocando a los dioses de la salud.

Giove (2006) señala que en la selva del Perú se denomina ícaro al canto o melodía que utilizan los curanderos durante los trabajos rituales que realizan. El "ícaro" es el canto chamánico, el arma curativa, la sabiduría y el vehículo de la energía personal del curandero, el símbolo de su poder durante los rituales. El maestro guía, transmite al aprendiz para que capte el conocimiento y así va cediendo "sus" ícaros, pues cada chamán tiene su propio ícaro, su experiencia y sabiduría que recibió de su maestro o directamente de la naturaleza. Los curanderos aprenden los ícaros durante el sueño o estado de conciencia [trance] de las "plantas maestras" que les dieron y captaron la melodía, en algunos casos en idiomas desconocidos.

Ochoa (2002) señala que cada chamán en Loreto tiene sus particularidades sobre el uso de las hierbas y cortezas de árboles (psicoactivos). Los antiguos tupinambas y tupí-omaguas usaban la flauta; los cocamas usaban en la danza la chacapa (parecido a una escobilla) y las yaguas, ticunas, chayahuitas y aguarunas, usaban la zampoña, tambor, maraca y flauta. Los ícaros son cantos religiosos usados por los pueblos indígenas amazónicos para ingresar al estado del conocimiento visionario (ECV), como ayahuasca, toé, chacruna, chuchuhuasi y tabaco. En los tupis cocamas el chamán actúa en el estado chamánico de la conciencia (ECC), con la ayuda de los espíritus protectores y auxiliares; los chamanes viajan a cualquier parte del mundo por agua, aire, se transforman en peces, pájaros, surcan ríos, mares, hasta atravesar los cielos.

Fericgla (1998) define que la música es entendida como sonido organizado con un orden impuesto por el ser humano de acuerdo a sus contingencias históricas y cognitivas, cuyo contenido es entendido por la colectividad que la compone, la interpreta y la mantiene viva. Desde la antropología, el principal elemento cultural relacionado con la música es la religión y, dentro de ella, la búsqueda de estados extáticos y de arrebatos emocionales, cuya expresión es la música chamánica.

Luna (1992) señala que los vegetalistas de Loreto y Ucayali curan con tabaco y plantas psicotrópicas; usan cantos llamados ícaros para comunicarse con el mundo de los espíritus de la naturaleza y el universo, para ejercer sus poderes. El período de iniciación dura algunos meses o varios años; bebe periódicamente la ayahuasca, previa dieta y abstinencia sexual y las madres de las plantas sagradas se presentan y enseñan al principiante. El chamán aprende la música de los espíritus de las plantas, animales, piedras y lagos, durante las visiones y cada planta tiene su propio ícaro y este es usado para curar determinadas enfermedades. Existe una jerarquía de ícaros, cada chamán tiene uno en secreto y, si canta en lengua indígena, tienen más poder.

Junquera (1989) explica que el chamán en los harakmbet es un terapeuta que cumple su misión curativa. Los cantos pueden coincidir en la letra, pero nunca en el ritmo ni en la entonación, pues los chamanes tienen cuidado con sus «claves secretas» a fin de que no sean robadas por nadie. El enfermo recupera la salud quebrantada con el empleo de canciones, gráficos, olores y belleza, proporcionadas por los espíritus de las plantas y animales.

Velásquez (1987) explica que, a los dioses, semidioses y espíritus auxiliares les gusta escuchar el canto, sonidos de instrumentos musicales y bebidas embriagantes. Las sonajas e audiófonos de sacudimiento, están asociadas al cosmos. Las flautas, silbatos y cañas sonoras están asociados al nacimiento del ser humano y al nacimiento del mundo. El arco musical está asociado al arcoiris, instrumento de comunicación, con los espíritus buenos y adversos. El turu-turu, instrumento musical de caña, está asociada con el espíritu de los perros primigenios y el ala del murciélago ayuda al chamán a comunicarse con los espíritus de los muertos. Los antepasados de los chamanes fueron creadores de los instrumentos musicales, cuyos espíritus viven ahora en las raíces más profundas produciendo sonidos de la naturaleza y otros ocultaron sus sonidos en el caparazón de las tortugas, armadillos, piedras y montañas. Estos animales eran señores festivos, investidos de musicalidad y sacralidad. El chamán es dueño del canto, del poema y de la música, porque es un ser inagotable y pertenece simultáneamente a dos mundos. La práctica chamánica renueva energías. 


\section{DISCUSIÓN}

\section{La música de sanación asháninka es ritual}

Es ritual porque el sheripiari ingresa como intermediario al mundo de los espíritus sagrados de la naturaleza (plantas, aves, insectos y animales), el universo (arcoiris, nubes, lluvia, vientos, rayos) y sheripiaris fallecidos. Después de beber la ayahuasca (banisteriopsis caapi), chirisanango (brunfelsia grandiflora), tabaco (Nicotiana tabacum), toe-toe o floripondio (Brugmansia suaveolens), el sheripiari desarrolla la ceremonia y Chirif (2016) señala:

Persona a la que se le atribuye la capacidad de modificar la realidad o percepción colectiva de esta. Tiene facultades de curar mediante el empleo de plantas y la interpretación de cantos. También se puede comunicar con los espíritus y tiene habilidades visionarias ( . . ), su preparación exige ritos de iniciación que incluyen largos ayunos, retiros y, en ciertos casos, ingestión de alucinógenos (p.94).

El sheripiari elige por discípulo. A un niño y como maestro le brindará una formación práctica, estricta y pasará por muchas pruebas hasta alcanzar el más alto nivel de formación. A su discípulo le traspasará los ícaros durante el estado alterado de la conciencia (EAC), y se sustenta en el testimonio:

La formación del aprendiz es estricta, soporta la prueba de las bebidas alucinógenas de ayahuasca, tabaco, toe-toe o floripondio, chirisanango; come sólo pescado asado, cogollo de plátano, yuca azada, nada de sal, ni ajī, tampoco carne de monte, masato ni relaciones sexuales. Si el aspirante cumplió con la prueba es un sheripiari; un sabio que puede convertirse en rayo, otorongo (Pantheraonca), águila (Aquila chrysaetos), pronostica el futuro, ve el tiempo pasado y presente. M. Rojas (comunicación personal, 24 de abril de 2019).

El aspirante a sheripiari recibe la formación de su maestro, en el bosque que es el santuario de los espíritus sagrados, rodeado de plantas medicinales, aves y hojas sagradas. La formación puede durar meses o extenderse varios años y es importante el testimonio:

En el territorio están los árboles sagrados, aves sagradas como el pitsioti ishivanti, pajarito con pluma a colores que deja caer, gota a gota, la medicina para los Asháninka; el sheripiari conversa y canta con los espíritus de las plantas, árboles, aves y animales del bosque; es el Tatsorentsi (Dios) de los verdaderos sheripiaris que crea alimentos y envía mensajes a los Asháninka cuando va a suceder algo. C. Pérez, (comunicación personal, 17 de octubre de 2019).
Todo lo anterior se sustenta en Vigotsky (2017) cuando señala:

Es el patrimonio que una generación transmite a la generación sucesiva, después de haberlo enriquecido con su propia contribución: de hecho, el niño no construye sus conocimientos desde cero, sino que se apoya en lo que sus antepasados han recogido y que él interiorizará y contribuirá a ampliar (p.60).

Los sheripiaris transmiten sus conocimientos experimentados a sus discípulos. Estos los adoptan innovando sobre los mismos.

Desde la concepción del mundo del pueblo asháninka de río Tambo, los recursos naturales del bosque tienen espíritus y, antes de ingresar, la gente debe limpiar o purificar su cuerpo y pedir permiso a "Ios dueños" o espíritus. Esto se sustenta en el testimonio cuando expresa: "Al que ingresa sin pedir permiso, los espíritus malignos le tiran sus municiones y al regresar sentirá dolor de cabeza, mareos, vómitos y sanará cuando el sheripiari lo cure" A. Shinchicama (comunicación personal, 28 de abril de 2019). También otro testimonio señala: "los peces, aves, animales, tienen espíritus y también su propio ivenki; para cazar el venado se usa el maniroivenki, para el sajino el shintoniroivenki y debe cazar sólo lo que pidió a los espíritus, si caza más comerá, pero se enfermará" Á. Marcos (comunicación personal, el 29 de abril de 2019). Los testimonios resaltan el uso racional de los recursos naturales y, si actúan en sentido contrario destruirán los ecosistemas naturales y la biodiversidad, se agotarán los alimentos y plantas medicinales y afectará la salud y alimentación de los pobladores.

Y para el pueblo asháninka de río Tambo, los espíritus del bosque premian con recursos a las personas que respetan al extraerlas y a las personas que no respetan los castigan enfermándolos; pues todo lo existente en el bosque tienen espíritus, evidenciando ser un pueblo panteísta y se sustenta en el testimonio:

Los espíritus tienen como jefe a mankite, entre los espíritus masculinos están el kamari (demonio), menkori (nube), tampea (viento), míronti (parecido al burro o mono), katsonkati (parecido a la cebra), katsiboreri (hombre pequeño), chullachaki (hombre que tiene un pie de venado), maranki (culebra), kaminkari (espíritu de los muertos), maninkarite (hombre protector de la naturaleza) y oyechari (arcoiris) entre los espíritus femeninos están kyantsi (sirena), irampabanto (espíritu de los árboles), viene con el aire lanzando sus municiones (piedritas, arenas, astillas, espinas, cáscara de yuca, hormigas, avejas) al cuerpo de bebés, niños y adultos hasta enfermarlos. C. Quentimari (comunicación personal, 29 de abril de 2019). 
De nuevo, lo anterior se sustenta en Vygotsky (2017, p.53) cuando señala que "la mente se enmarca en un contexto concreto hecho por historias, culturas, instituciones, organismos sociales, usos y costumbres, creencias, ideologías, tradiciones y expresiones artísticas" (p.53). Los pobladores Asháninka organizaron sus formas de vida adaptada al bosque tropical, para obtener los recursos y preparar alimentos, confeccionar la indumentaria, construir viviendas, organizarse; así como los temores, música, canciones (ícaros) y otros.

\section{La música de sanación Asháninka es medicinal}

Es medicinal o de sanación porque el sheripiari es médico, sacerdote, sabio que maneja el tercer poder, científico, visionario, compositor y maestro; es el intermediario entre lo humano y lo sagrado. Nicahuate (2007) señala que una persona está sana cuando no tiene dolencias en el cuerpo, trabaja, juega y camina por distintos lugares. Y una persona está enferma cuando presenta dolencias en todo el cuerpo, permanece en cama y no puede trabajar ni caminar y las enfermedades son provocadas por los espíritus malévolos del bosque. Y se sustenta en Regan (2011) cuando señala que "el chamán es el intermediario e intérprete de las relaciones entre el mundo sobrenatural y los humanos (...), ven a las plantas con forma humana y animales que hablan" (p.228). Es decir, los recursos naturales existentes en el bosque tienen vida y hay que utilizarlos racionalmente y el sheripiari ostenta el nivel intelectual más alto en el pueblo Asháninka. Asimismo, Cayón y Chacón (2014), sustentan que los cantos y curaciones del chamán están relacionadas con las actividades productivas, interactuando con los lugares sagrados; porque la pesca, caza, recolección y extracción de materiales, tienen espíritus con poderes por lo que, al ser extraídas sin permiso, producen enfermedades y muertes; pero si se extraen pidiendo permiso transmiten conocimientos. Por ello los asháninkas tienen un profundo respeto por el bosque, mientras que para la sociedad occidental hay que extraer y vender los recursos existentes en el mismo.

En las ceremonias de curación, el sheripiari es un mediador entre lo humano y lo sagrado-natural; recibe el mensaje de los espíritus sagrados del bosque y el universo y se sustenta en el testimonio "el rayo traía a la candela, a la música y lo dejaba en el árbol de ungurawi y el sheripiari lo recogía para enseñar a los demás". C. Pérez (comunicación personal, 29 de abril de 2019). Esto también se encuentra sustentado en otro testimonio:

En el territorio comunal está el bosque, los cerros, variedades de ivenki o piri-piri (eleutherine bulbosa miller), para curar nuestro cuerpo, hojas sagradas (kaviniri, coca silvestre, canela); árboles sagrados (almendra, tsirintsi, ungurawi); en el huayruro (ormosia coccinea) viven animales que emiten voces de seres humanos que cantan canciones sentimentales. A. Ramírez (comunicación personal, 9 de agosto de 2019).

Los árboles, animales y aves sagradas (religión) están en el bosque sagrado, el "santuario" (templo, iglesia), el sheripiari como "compositor" (creador de los ícaros), el "guía espiritual" (cura o sacerdote), el "visionario" (recoge la medicina que mandan los espíritus), el "médico" (sanador) y para sustentarlo acudimos al testimonio:

El sheripiari está en el bosque, en las hierbas sagradas como el inchatoshi, tsipanashi, la canela silvestre, uña de gato, cascarilla o quinaquina, chuchuhuasi, kaviniri, coca silvestre para curar el mal aire, arcoiris, susto, chacho y cerro. J. Rodríguez (comunicación personal, 9 de agosto de 2019).

El sheripiari cura a los pacientes con hierbas medicinales que envían los espíritus sagrados con música e ícaros sagrados lo cual es sustentado por Chirif (2016), cuando explica que el "Ícaro. [es un] Ensalmo dirigido por los chamanes a los seres invisibles para pedirles apoyo a fin de curar a un enfermo, proteger a una persona de influjos negativos o invocarlos para tener una visión" (p.153). Asimismo, reitera que "Icarar. [Es la] Acción de proteger a una persona u objeto a través de ícaros o encantos mágicos. Acto de curar a una persona con ícaros y soplos de humo de tabaco, tarea realizada por curanderos y chamanes" (p.153). 153).

La enfermedad en las culturas amazónicas cruza por lo sagrado, el ser humano y la comunidad. El chamán realiza esta práctica social, cultural y afectiva muy cerca a los pacientes que confían y esta situación favorece su acción terapéutica (Estrella, 1995; Rojas-Bolivar, 2014). Los pobladores confian en el sheripiari para el tratamiento de las enfermedades culturales como el susto, mal aire, arcoiris, cerro, entre otros. Incluso algunas personas de las ciudades acuden a las sesiones del sheripiari para tratarse de enfermedades psicosomáticas.

El sheripiari, después de haber bebido los alucinógenos como la banisteriopsis caapi, brugmansia suaveolens, maytenus laevis, nicotiana tabacum, psychotria viridis, cinchona pubescens, erythroxylum coca, cinnamomum zeylanicum, uncaria tomentosa l., entre otros, empieza a entonar los ícaros de sanación sobre el paciente con voz suave, variando la melodía, ritmo y ánimo en función al estado emocional del mismo. Asimismo, Córdoba et al. (2012) citados por Ávila-Carbajal et al. (2019), señalan que los rituales del yagé o ayahuasca en las investigaciones demostraron el potencial sanador 
de la limpieza psíquica y corporal, generando una especie de catarsis, que permite liberar las tensiones y reorganizar el sistema alimenticio y los estilos de vida.

Los verdaderos sheripiaris curan con música, ícaros y plantas sagradas en un lugar sagrado del bosque; no utilizan locales y no cobran dinero, tampoco realizan propaganda por emisoras radiales. El sheripiari o chamán cura las enfermedades causadas por los espíritus malignos como el susto (sirenas, boas, caídas, ruidos), abuelo o chacho (cerros, rocas), dolores de cabeza, vómitos, rapto del alma y el cutipado, incluso el insomnio, vómitos, gastritis, problemas respiratorios, dolores corporales, punzadas en el cuerpo y sudoración (Vargas, 2013); conocidas como las enfermedades psicosomáticas del siglo XXI. Asimismo, TangarifePuerta et al. (2018) afirman que el chamanismo representa una reprogramación de la mente y que se logra mediante la danza, plantas sagradas, canto, meditación y abstracción. Incluso el ritual, no es universal, se diferencian en cada realidad histórica y cultural. En general el chamán, aniquila a los enemigos, sana a las víctimas y salva a su pueblo del hambre y las enfermedades (Martínez, 2019; Rodríguez, 2011).

\section{La música de sanación Asháninka es estética}

Es estética porque su música, canciones (ícaros), colores, temores, emanaciones y conductas, expresan la armonía con el medio en el que viven. Los sabios y mayores transmiten la manifestación artística a las nuevas generaciones, como la música pantsantsi sheripiari y el canto apampoya sheripiari, previa purificación espiritual de sentimientos y pensamientos. Y se sustenta en la teoría históricocultural de Vygotsky (2017), cuando señala que "se modelan dentro de los límites de una dimensión social concreta, con sus propias características, únicas e irrepetibles" (p.59). La música e ícaros de los sabios asháninkas se diferencia de la música de otras culturas de la región Junín y el país.

El disfrute estético de la música y el canto (ícaro) viene de que estos tienen un fin ritual, un medio de conexión con la naturaleza y la sanación espiritual; es decir un mediador entre lo humano y lo sagradonatural. Para relacionarse con la naturaleza, los asháninkas, realizan rituales de "limpieza del cuerpo" antes de ingresar al bosque y es importante que el sheripiari sea el "compositor" y, a la vez, el "guía espiritual", demostrando así la utilidad ritual que se le asigna a la música. El canto y la música asháninka, constituyen una obra de disfrute estético, centrada en la religión, "lo sagrado", "lo espiritual". La base material de la música y las canciones (ícaros), está en el bosque, en la naturaleza y el universo; además, lo abstracto está expresado en el panteísmo; en los espíritus de la naturaleza (plantas, lagunas, ríos, árboles, peces, animales, aves, cerros) y el universo (el rayo, lluvia, viento, nubes, arcoiris), entre otros.

El pueblo, asháninka de la cuenca del río Tambo, como cualquier otro pueblo, desarrolló la estética a partir del chamanismo, al beber plantas alucinógenas, como chuchuhuasi (maytenus laevis), ayahuasca (nanisteriopsis caapi), tabaco (nicotiana tabacum), toé o floripondio (brugmansia suaveolens), chacruna (psychotria viridis), chirisanango (brunfelsia grandiflora), coca silvestre (erythroxylum coca), canela silvestre (cinnamomum zeylanicum), durante las sesiones chamánicas curándose con la armonía de los ícaros y la música tradicional. La estética está expresada en la lengua materna, en los pagos a la madre tierra ina kipatsi, madre del bosque ashitarori antamishi, madre del árbol oniro inchato, arcoiris oyechari. Asimismo, en las sesiones chamánicas, los pacientes muestran expresiones de felicidad, alegría, nostalgia, tristeza, dolor, sufrimiento y heroísmo.

Las canciones tienen espíritus que acompañan a la cantora, como este testimonio explica: "La tsameto, maestra asháninka le enseñó a mi hija a tomar el ivenki (piri-piri), para que cante canciones sentimentales, mientras va hilando o tejiendo y sea una mujer dulce y aprenda a tratar bien a la gente". Á. Ramírez (comunicación personal, 23 de octubre de 2019)

Asimismo, Chirif et al. (1988), hallaron que "Los hombres y las mujeres campa cantan en las fiestas nocturnas, en las "masateadas". El canto une al grupo en noches de luna, el canto expresa sentimientos amorosos, tristezas, alegrías o preocupaciones" (p.127). También hombres y mujeres utilizan la pintura facial con achiote (bixa orellana); pintura corporal con huito (genipa americana), para verse atractivos(as), seducir, enamorar y protegerse de los espíritus malignos y evitar enfermedades.

\section{La música de sanación asháninka es interpretada con instrumentos musicales tradicionales}

Es interpretada con instrumentos musicales tradicionales porque estos son sagrados y los Asháninka aprendieron a interpretar desde tiempos inmemoriales la antara (sonkari), tambor (tamporo), huesos de perdiz (imovento), entre otros. El sheripiari asháninka es un ser inagotable, pertenece simultáneamente a dos mundos y en la mayoría de ícaros (canciones) canta a la naturaleza y al universo. Es "místico y poeta, el chamán compone canciones y tonadas capaces de hechizar los sentidos $e$ inducir al trance extático a quienes le escuchan" (Sánchez, 2011, p.48). La ceremonia de curación acompaña el sheripiari con canto y música. 
Algunos sheripiaris o chamanes emplean la flauta, zampoña, tambor, maraca y, en otros lugares, utilizan los sonajeros, tambores, idiófonos de sacudimiento; instrumentos hechos de caña (flautas, antaras y maracas); instrumentos de alfarería (silbatos y ocarinas); instrumentos de huesos (cráneos de jaguares, venados, monos, aves). Otros obtienen la música frotando caparazones de tortuga, armadillo, trompetas de cuerno (corna). Incluso, tocan el arco musical asociado al arcoiris, el turuturu asociado al espíritu de los perros primigenios y ala del murciélago para ayudar al chamán a viajar por el mundo de las tinieblas y comunicarse con los espíritus de los muertos (Ochoa, 2002; Velásquez, 1987). También hay géneros musicales y signos afectivos asociados con la curación en cada cultura que curan los trastornos como la pérdida del alma y el susto (Olmos, 2008). Asimismo, Trujillo et al.; (2010), sostienen que el yagé o ayahuasca (banisteriopsis caapi), funciona en cada contexto histórico y cultural. Incluso refleja la calidad de vida y salud de los pueblos indígenas u originarios, como es el caso de los Asháninka que viven en lotes y parcelas, en relación a los Asháninka que viven en un territorio con bosques sagrados.

\section{La música de sanación Asháninka es colectiva}

Es colectiva porque la música y el canto del sheripiari es una expresión artística; pues la música y el canto, estos son transmitidos y socializados al interior de la familia y la comunidad. DomicoMurillo (2019) señala que hay cantos de animales, cantos de sanación, cantos de duelos, cantos de arrullos y cantos de parejas. En la comunidad, algunas mujeres adultas y ancianas cantan y bailan; los varones tocan (zampoñas, flautas, tambores, semillas, maracas); también en reuniones familiares (cumpleaños, pesca, aniversarios) y está arraigada en la comunidad. Además, se sustenta en el testimonio: "la música y canciones asháninka, no tiene sentido comercial, sólo para alegrar y bailar con la familia" C. Pérez (comunicación personal, 26 de octubre de 2019).

Los Asháninka de las comunidades de la cuenca del río Tambo cantan la música ancestral, como expresa el testimonio: "cantamos en agradecimiento a ina kipatsi (madre tierra) que nos da alimentos, al bosque que nos da frutos y animales, al río que nos da peces, cantamos con tristeza por la destrucción del bosque, invasiones y la contaminación del río". C. Quentimari (comunicación personal, el 9 de agosto de 2019). La música Asháninka tiene códigos musicales propios, inéditas y no está incorporada en la comunidad académica, ni en el mercado artístico. La composición musical tiene propiedad colectiva y el testimonio nuevamente expresa: "las canciones son de la comunidad". Y. Sánchez (comunicación personal, 30 de abril de 2019). La letra y música no pertenece a una persona, sino a la colectividad y a la sanación de la comunidad Asháninka.

En selva central surgieron conjuntos tropicales, interpretados por jóvenes Asháninka que manejan instrumentos musicales electrónicos y se sustenta en el testimonio: "Está formado por asháninka, netos campas de Perené, Pichanaki, Satipo y tocan cumbias tropicales que están sonando en toda la Amazonía". S. Román (comunicación personal, 19 de agosto de 2019). Además, la agrupación "Invasión Asháninka", adaptó a la cumbia tropical algo de la música chamánica como el "chullachaqui", "piripir" y "San Juan". Mientras en Atalaya el conjunto tropical "El Cacique del Menkoremon y su Cuarteto Atalaíno"; también en sus composiciones adaptó algo de la música chamánica, como "warmi icaro", "sheripiari", "kamarampi" y "ayahuasca". Esta música de género tropical tiene fines comerciales y divertir a los jóvenes.

\section{Conclusiones}

1. Es ritual, porque la música e ícaros de sanación es religiosa; su base material es la naturaleza que constituye el santuario o templo de los espíritus sagrados de plantas, árboles, aves y animales. Además, previa purificación espiritual, la música es transmitida a las nuevas generaciones, y sirve como medio de conexión con el bosque y los espíritus sagrados.

2. Es medicinal, porque las plantas medicinales tienen un carácter material y la medicina es un elemento de la naturaleza; mientras que la música del sheripiari es un mediador entre lo humano y lo sagrado. Además, cura las enfermedades psicosomáticas como el susto (sirenas, boas, caídas, ruidos), abuelo (cerros, rocas), arcoiris (hemorragias), dolores de cabeza, vómitos, rapto del alma y el cutipado (efectos negativos en niños(as); incluso las enfermedades del siglo XXI, como el estrés, dolor de articulaciones, gases en el estómago, entre otros.

3. Es estética, porque la música tradicional Asháninka es una manifestación artística expresada en la creatividad de los sentimientos y pensamientos. La base material es el manejo racional del bosque. Además, la medicina es un arte de la naturaleza que da vida y es trasladada al ser humano mediante las plantas medicinales. El disfrute estético es el ritual del sheripiari como "compositor" y "guía espiritual".

4. Es interpretado con instrumentos musicales tradicionales, porque la música de sanación Asháninka se trasmite en forma oral y al oído; en la composición musical, el sheripiari incorpora sonidos de la naturaleza con sus propios códigos y se ubica en una nueva línea 
musical. La música y el canto son anónimos y los instrumentos musicales son confeccionados por sheripiaris y mayores.

5. Es colectiva, porque la música y canciones de sanación son transmitidas y compartidas en la vida comunitaria y en reuniones familiares. Está arraigada en el ámbito comunal (cumpleaños, pesca, masateos) y no tiene sentido comercial, como las artistas y orquestas típicas del centro del Perú.

\section{REFERENCIAS}

Alegría, E. (2018). Los ícaros: caracterización del elemento musical como medio de sanación en el ritual de toma de yagé del taita Marcelino Chicunque. Sibundoy, Putumayo (Tesis de pregrado, Universidad del Valle). https://bibliotecadigital.univalle.edu.co/xmlui/ bitstream/handle/10893/12259/0582453-3350-S. pdf?sequence $=1$

Ávila-Carbajal, J., Pedroza, M. y Angulo, Ó. (2019). Yagé: Crisis de occidente y trabajo espiritual Yagé, Univ. Salud, 21(3), 240-252. DOI: http://dx.doi.org/10.22267/ rus.192103.161

Cayón, L. y Chacón, T. (2014). Conocimiento, historia y lugares sagrados. La formación del sistema regiona del alto río Negro desde una visón interdisciplinar, Anuário Antropológico, 39(2) 201-233. https://doi. org/10.4000/aa.1294

Chirif, A., Varese, S. y Roel, J. (1988). Voces e instrumentos de la selva: Aguaruna, Campa. Revista Latinoamericana de actualidad y análisis, 13(45,46), 123-136. https:// sites.google.com/site/marareq/musicaperuana-bibliografia/amazonia

Chirif, A. (2016). Diccionario Amazónico: Voces del castellano en la selva peruana, Lluvia Editores, Región Loreto. https://www.caaap.org.pe/producto/diccionario-amazonico-voces-del-castellano-en-la-selva-peruana/

Domico-Murillo, N. (2019). Guardianas de la sabiduría: Pedagogía de los cantos ancestrales del pueblo Embera Eyabida. Uni-Pluriversidad, 19(1), 56-71. https://doi. org/10.17533/udea.unipluri.19.1.04

Estrella, E. (1995). Biodiversidad y salud en las poblaciones indígenas de la Amazonía [Archivo PDF]. Secretaría Pro Tempore del Tratado de Cooperación Amazónica. http://www.otca-oficial.info/assets/documents/20160704/f261e0083894b8e45325752093e93c26.pdf

Fabián, B. (2016). La educación Asháninka en comunidades nativas de la cuenca del río Tambo [Tesis doctoral, Universidad Nacional del Centro del Perú]. http://181.65.200.104/bitstream/handle/ UNCP/4154/Fabian\%20Arias\%20Beatriz.pdf?sequence $=1$ \&isAllowed $=y$

Fericgla, J. (1998). La relación entre la música y el trance extático [Archivo PDF]. Fundación Josep M. Fericgla.
https://josepmfericgla.org/web_Fundacio_JMFericgla_2/pdf/josep_maria_fericgla_la_relacion_entre_la_musica_y_el_trance_exctatico.pdf

Giove, R. (2006). Acerca del "Icaro" o canto chamánico. AYAHUASCA-MEDICINA. https://komikamewordpress. com/ayahuasca-y-plantas-maestras/icaros/

Hammersley, M. y Atkinson, P. (1995). Etnografía: Métodos de investigación ( $2^{a}$ ed.). Paidós Básica. http://webdelprofesor.ula.ve/humanidades/franco/Materiales\%20de\%20apoyo\%20didactico/Etnografia.\%20 Metodos\%20de\%2OInvestig\%20-\%20Hammersley,\%20Martyn\%20y\%20Atkinson,\%20.pdf.pdf

Junquera, C. (1989). Alucinógenos y chamanismo en la tribu Harakmbet. Revista Española de Antropología Americana, 19, 207-227. https://dialnet.unirioja.es/ servlet/articulo?codigo $=623184$

Lagunas, J. (2011). Los ícaros. Canciones de poder del chamán. AYAHUASCA-MEDICINA. https://komikame. wordpress.com/ayahuasca-y-plantas maestras/ icaros/

López, S. (2016). La vida como proceso de sanación: prácticas chamánicas del alto Amazonas en torno a la ayahuasca en España [Tesis doctoral, Universidad Complutense de Madrid]. E-Prints Complutense. https://eprints.ucm.es/id/eprint/37817/

Martínez, R. (2009). El chamanismo y la corporalización del chamán: Argumentos para la deconstrucción de una falsa categoría antropológica, Cuicuilco, 16(46), 197-220. http://www.scielo.org.mx/scielo.php?script=sci_arttext\&pid=S0185-16592009000200010

Murillo, J. y Martínez, C. (2010). Investigación Etnográfica: Métodos de investigación educativa en educación especial [Archivo PDF]. http://www.uam.es/personal_pdi/stmaria/jmurillo/InvestigacionEE/Presentacione/Curso_10/I_Etnografica_Trabajo.pdf

Nicahuate, J. (2007). El Sheripiari como agente socializador a través de la práctica médica en la cosmovisión ashéninka, Plural editores, La Paz-Bolivia [Tesis de pregrado]. http://bvirtual.proeibandes.org/publicaciones/publicaciones/29.pdf.

Ochoa, J. (2002). Mito y Chamanismo: El mito de la tierra sin mal en los Tupi-Cocama de la Amazonía Peruana [Tesis Doctoral, Universidad de Barcelona] TDX (Tesis Doctoral en Xarxa). https://www.tdx.cat/bitstream/handle/10803/2033/TESISOCHOA.pdf?sequence $=3$ \&isAllowed $=y$

Organización de las Naciones Unidas para la Educación, la ciencia y la cultura-UNESCO (2011). Los conocimientos tradicionales de los chamanes jaguares de Yuruparí. UNESCO. https://ich.unesco.org/es/ $\mathrm{RL} /$ los-conocimientos-tradicionales-de-los-chamanes-jaguares-de-yurupari-00574

Olmos, M. (2008). Música, trance y curación: El caso del Noroeste de México. En C. Bonfiglioli, A. Gutiérrez y M. A. Olavarría Ma. (coords). Las vías del Noroeste III, en prensa (pp. 366-388). Universidad Nacional Autónoma de México. https://www.researchgate.net/ publication/330567137_Musica_trance_y_curacion_el_caso_del_noroeste_de_Mexico 
Rodríguez, J. (2011). Cosmovisión, chamanismo y ritualidad en el mundo prehispánico de Colombia. esplendor, ocaso y renacimiento. Haguaré, 25 (2) 145-195 Universidad Nacional de Colombia.

Regan, J. (2011). Hacia la tierra sin mal: La religión del pueblo en la Amazonía ( $3^{a}$ ed.). Ediciones Centro Amazónico de Antropología y Aplicación Práctica (CAAAP) y Centro de Estudios Teológicos de la Amazonía (CETA).

Riviére, A. (1996). La teoría psicológica de Vygotski. Ediciones del Salmón.

Rojas-Bolívar, D. (2014). Ayahuasca: el encuentro de dos paradigmas. Revista de Neuro-Psiquiatría, 77(1), 40-47. https://www.redalyc.org/pdf/3720/372033985005 pdf

Sánchez, M. (2011). La huella del chamán: Mitos y rituales de una espiritualidad ancestral, Revista Pucara, 23, 43-64. https://issuu.com/filosfia/docs/la_huella_ del_chaman $/ 5$

Tangarife-Puerta, H. F., Ceballos-Ceballos, L. A. y Rodríguez-Osorio, J. E. (2018). Chamanismo, enteógenos y arte contemporáneo, Revista Cultura y Droga, 23(25), 106-136. http://190.15.17.25/culturaydroga/ downloads/Culturaydroga23(25)_07.pdf

Trujillo, E., Frausin, G., Correa, M. y Trujillo, W. (2010). El uso de la ayahuasca en la amazonia. Ingenierías \& Amazonia, 3(1), 151-163. https://eprints.lancs.ac.uk/id/ eprint/76140/1/Trujillo_et_al._2010.pdf
Quirce, C. (2010). El chamanismo y las drogas enteogénicas/ alucinatorias del mundo precolombino. Revista Costarricense de Psicología, 29(43), 1-15. https:// www.researchgate.net/publication/323713038_ El_chamanismo_y_las_drogas_enteogenicasalucinatorias_del_mundo_precolombino/fulltext/5aa73562a6fdcccdc46a9383/El-chamanismo-y-las-drogas-enteogenicas-alucinatorias-del-mundo-precolombino.pdf

Vargas, P. (2013). Las enfermedades psicosomáticas y el malestar emocional de los (as) estudiantes de la Sede del Atlántico. Revista de las Sedes Regionales, 14(28), 5-24. https://www.redalyc.org/ pdf/666/66629446001.pdf

Velásquez, R. (1987). Chamanismo, mito y religión en cuatro naciones étnicas de América aborigen. Academia Real de la Historia.

Vygotsky, L. (2017). La escuela histórico-cultural. Salvat.

\section{Fuentes de financiamiento.}

La investigación fue realizada con recursos propios.

\section{Conflictos de interés}

La autora declara no tener conflicto de interés.

\section{Correspondencia}

Beatriz Anastacia Fabián Arias

El Tambo/Huancayo, Perú

920200096

fabianbeatriz4@gmail.com 